\title{
A path to actionable climate science: perspectives from the field
}

\author{
Nicole M. DeCrappeo ${ }^{a} \bowtie$, Gustavo A. Bisbal ${ }^{a}$, and Alison M. Meadow
}

\author{
aU.S. Department of the Interior Northwest Climate Science Center \\ 777 NW $9^{\text {th }}$ Street - Suite 400 \\ Corvallis, OR 97330-6169, USA \\ Phone: 541-750-1021 \\ Fax: 541-750-1069 \\ Email: ndecrappeo@usgs.gov ( $\varangle$, corresponding author)
}

'Institute of the Environment, University of Arizona

1064 E. Lowell Street

PO Box 210137

Tucson, AZ 85721-0137, USA

\section{Abstract}

The U.S. Department of the Interior Climate Science Centers (CSCs) work with natural and cultural resource managers and scientists to gather information and build tools needed to help fish, wildlife, and ecosystems adapt to the impacts of climate change. The CSCs prioritize the delivery of actionable science products (e.g., synthesized scientific information, maps, decision support tools, etc.) that are focused on key management priorities and co-produced by teams of scientists and managers. In the specific case of the Northwest CSC, we have been successful at promoting and supporting the coproduction of actionable climate science at the individual project level, but it has been more difficult to 
replicate this success at the regional program level. Here we identify the most significant challenges in satisfying this mandate and propose the creation of a Science Advisory Panel to provide improved interface between resource managers and scientists engaged with the Northwest CSC.

\section{Keywords}

Natural and cultural resource management; actionable climate science; co-production of science; manager-scientist engagement; U.S. Department of the Interior Climate Science Centers

\section{Acknowledgements}

We are grateful for the thoughtful and constructive suggestions from Robin O'Malley and two anonymous reviewers. A. Meadow was supported by U.S. Department of the Interior Southwest Climate Science Center Award G13AC00326. Any use of trade, firm, or product names is for descriptive purposes only and does not imply endorsement by the U.S. Government. 


\section{Introduction}

The eight regional U.S. Department of the Interior (DOI) Climate Science Centers (CSCS) are faced with a daunting challenge: help DOI bureaus, as well as other federal, tribal, and state entities, understand and adapt to climate change impacts on their managed resources. As funders of climate change science, impacts assessments, and adaptation research, the CSCs must carefully consider how to best invest their limited research dollars. The success of this strategic investment hinges on a clear understanding of priority resource management concerns and the ability to tap into a diverse and multidisciplinary regional scientific community.

Delivering actionable climate science to natural and cultural resource managers is a commitment that all CSCs have embraced since their inception as a proper and effective use of the research funds they each administer. As the multi-stakeholder federal Advisory Committee on Climate Change and Natural Resource Science (ACCCNRS) defines it, actionable science "provides data, analyses, projections, or tools that can support decisions regarding the management of the risks and impacts of climate change. It is ideally co-produced by scientists and decision-makers and creates rigorous and accessible products to meet the needs of stakeholders" (ACCCNRS 2015). This definition seems straightforward, but putting it into practice can be difficult, as the objectives, processes, reward systems, and funding mechanisms of academia, governmental resource management agencies, and onthe-ground practitioners do not always align well with the objectives and processes required to produce actionable science (Roux et al. 2010; Bell et al. 2011; Reed et al. 2014; Cvitanovic et al. 2015). Here we describe the Northwest CSC (NW CSC) process for, and challenges in, producing actionable climate science at both the project (or site) and program (or regional) levels. We further describe our approach to transform this process into a more robust, action-oriented dialogue through our recent creation of a Science Advisory Panel (SAP), which parallels our existing Stakeholder Advisory Committee (SAC).

\section{How are CSCs currently supporting co-produced actionable science?}


While the concept of co-produced actionable science as it relates to climate change is relatively new, much has already been written on the role "boundary" organizations, like CSCs, that work at the interface of the research and management worlds play in the process of linking science and decision making (Guston 1999; Cash 2001; Guston 2001; Lemos and Morehouse 2005; Dilling and Lemos 2011; Meadow et al. 2015). For the CSCs, the notions of generating management-relevant scientific outputs (i.e., actionable science) and encouraging scientists to work in tandem with managers (i.e., coproduction) have early roots in the foundational Secretarial Order that established the centers (DOI 2009). The actionable science development process as described by ACCCNRS and that we refer to in this paper is one in which scientists and managers 1 ) initially discuss a management priority that needs to be addressed, 2) collaboratively decide on a scientific strategy to help inform decisions around that priority, 3) converse regularly and meaningfully throughout the venture, and 4) generate scientific information and products that the managers can use to address the original management priority. The steps along this path are not trivial nor necessarily straightforward for scientists and managers indoctrinated in the cultures, communication norms, and reward systems of their respective institutions and organizations. However, as Beier et al. (2016) describe, operating in traditional ways - for example, scientists relying on managers to find important scientific results in the peer-reviewed literature (i.e., the "loading dock" approach (Cash et al. 2006)) - is simply not effective when dealing with complex climate change issues. They argue that the co-production process is far more successful in helping scientists design studies that address real-world management priorities while also helping managers understand both the promise and limitations of scientific products. Boundary organizations have been suggested as one way to facilitate the co-production of decision-relevant knowledge because they 1) explicitly involve actors from both sides of the boundary as well as professionals who serve a mediating role, 2) exist at the frontier of the two different social worlds of policy and science and are accountable to each, and 3) provide opportunities to create shared products, often called boundary objects, which 
are meaningful to both sets of actors (Guston 1999; 2001). Cash (2001) added a fourth function, which is particularly relevant to the NW CSC: linking science and decision making across different levels of organization of natural resource issues.

Linking science and decision making through the co-production of actionable climate science is one of the cornerstone services that CSCs provide to their respective regional communities. At the NW CSC, this service is intended to occur at two levels of organization: the project (or site) and program (or regional) levels. At the project level, the NW CSC generates actionable science by strongly encouraging, and financially supporting, close working relationships between scientists (i.e., principal investigators or PIs) and resource managers (Fig. 1A). This administrative control over project selection and the awarding of funds allows the NW CSC to stipulate, for example, that PIs must identify specific resource managers with whom they intend to work throughout the life of the project. The process might play out like so: following conversations with regional forest managers about their most pressing climate-related concerns, a NW CSC-funded PI produces a time-series of maps of potential future distribution of an ecologically important tree species. These maps are intended and designed to help the forest managers decide where to take specific conservation actions for that species in the near and/or long term. This, at a very fundamental level, is what we consider to be a process of co-production of actionable science: it begins and is continuously infused with a dialogue on the priorities of managers and capacity of scientists; it results in scientific products tailor-made to address those management priorities and implementation steps that can be taken with the resulting scientific products in hand.

From the NW CSC perspective, the communication and information flow between scientists and resource managers generally works well at the project level. However, CSCs also have responsibilities related to facilitating collaboration at regional scales. Often, management priorities are set at these larger scales, landscapes are shared across multiple agencies or owners, and areas of concern overlap with multiple actors taking responsibility for particular issues. These large-scale, multi-agency concerns 
will require collaboration, joint knowledge-production, and joint decision making at regional scales.

However, when considering the co-production of actionable climate science at the program or regional level, we encounter challenges related to three constructs: 1) the communication pathways intrinsic to the resource management entities the NW CSC works with, 2) the ability of management organizations to clearly articulate their management priorities, and 3) the NW CSC's current operational configuration (Fig. 1A).

The first challenge is the uncertain or inconsistent link between an organization's on-the-ground managers, who are directly engaged in the co-production process at the project level, and its regional executives and decision-makers, like those involved in our Stakeholder Advisory Committee (SAC). The $\mathrm{SAC}$ is a construct that assembles executives (or their designees) from federal, tribal, and state natural and cultural resource management organizations in each CSC region. One of their primary functions is to provide guidance on their organizations' management priorities (note: CSC SACs operate according to common Terms of Reference drafted by the USGS National Climate Change and Wildlife Science Center (NCCWSC 2014); the Terms of Reference outline the eligible participants, structure, and function of the SACs). Every SAC member organization has its own framework for using and sharing information, often called an "information use environment" (Taylor 1991; Choo 2006), which defines the communication channels for the traffic of formal and informal messages between sources and receivers through layers of sequential authority. While much depends on the complexities, efficiencies, and limitations inherent to any particular organization's information use environment, our experience suggests that actionable scientific products delivered at the on-the-ground manager level often come to a dead end at that very level, without propagating any further up the organization's chain of command. When this is the case, no one in the organization other than the ground-level manager who was engaged in the project is aware of, or has the ability to effectively use, the project's scientific products. While this breakdown in information sharing may not happen in all agencies all the time, we have witnessed instances in which 
incomplete communication has kept new research findings from being shared within organizations, thus limiting their potential utility or impact. Of course, executives and decision-makers like those on the SAC generally have different information needs than ground-level managers, and the two groups may be failing to connect effectively because they are viewing priorities, needs, and existing information from different perspectives and scales of interest. Attempting to alter the internal communication pathways of the many organizations the CSCs work with is outside of the scope of the CSCs' mission and institutional authority. Instead, we wish to create opportunities to work with the status quo, yet still improve information sharing about new climate change research and products.

A second challenge to sustainable production of actionable science at the program level consists of the degree to which regional executives are able to clearly articulate their organizations' top climaterelated management priorities. CSCs were designed to learn the management priorities of their regions from their respective SACs. The CSCs then recognize these priorities as the basis for developing and updating their respective 5-year Science Agendas and commission decision support tools, recruit scientific experts, and fund research projects to address those Science Agenda items. To be sure, the delivery of understandable management priorities is an essential first step in the process of delivering actionable science. Our observation over the years, however, reveals that when asking resource managers what their organization's management priorities are, it is not unusual to hear answers that begin with: "Our science needs are..." Not surprisingly, the responses continue with a recitation of lengthy lists of scientific products, data, projections, models, or tools that managers wish to have, but still without an explicit description of their intended management application. This shortcoming in the ability to convey concrete management priorities adds to the overall communication breakdown depicted by the hatched arrow in Fig. 1A. Absent an explicit description of management drivers, scientists attempt to "fill in the blanks" by providing scientific products that, more often than not, fail to resolve any perceived management urgency. This communication challenge can leave CSCs and the 
scientists they support without management-relevant guidance and stifle the process of co-producing actionable science.

Finally, the third challenge we have experienced in co-producing actionable climate science at the program level stems from the CSCs' own organizational structure. Because SAC members and NW CSC-funded project PIs (especially those employed by research universities) do not have direct contact to one another, as illustrated in Fig. 1A, there appears to be a discontinuity in the flow of information to and from the SACs. At the NW CSC, scientific information has traditionally been conveyed to SAC members through regular email communications from NW CSC staff, updates to the NW CSC website, monthly newsletters with summaries of recent climate-related journal articles and scientific resources, and project presentations by NW CSC-funded PIs. We have found, however, that these information dissemination methods are not the most efficient or effective when it comes to addressing regional climate change management issues. Project-by-project presentations of results, for example, can make the discussion of findings too project-centric, too diffuse, or too disjointed to present a cohesive picture of scientific outcomes meaningful to the SAC or, importantly, to help inform executive-level decisions. The bottom line is that, from the NW CSC's perspective, there appear to be important missing pathways in the flow of climate change information for it to become fully actionable and co-produced at all levels. While the NW CSC is successfully supporting co-produced actionable science efforts between PIs and managers at the project level, additional actors and mechanisms are needed to achieve this with regional executives at the program level.

\section{Fulfilling our potential}

The original concept of CSCs was one in which federal resources were deployed in each region to contribute, to benefit from, and ensure integration with the established intellectual reservoir represented by academic institutions, USGS centers, and other science-producing organizations. From 
this position, CSCs would be able to facilitate a dialogue between their region's scientific experts and the resource management executives and decision-makers who participate in CSC SACs. The concept of the CSCs matches many aspects of boundary organizations, but they were not explicitly created with the characteristics of boundary organizations built in. What we perceive as lacking is a way to discover, interpret, channel, and apply the myriad relevant climate change research efforts taking place at the project level to the broad and general needs of resource managers at the program level. In other words, we wish to fully engage both the higher-level executives who can influence agency procedures and policies as well as the immediate end-users of climate information in a way that is effective regardless of the current information flows within the management entity. The NW CSC was not functioning as a boundary organization in an important way: it was not providing sufficient opportunities for policy makers (i.e., regional-level agency executives) to engage with scientists who could share research findings relevant to the policy makers' decisions and for scientists to be involved with decision-makers to gain a better understanding of the management contexts they work in. Lack of consistent engagement between the two groups contributes to lower levels of perceived credibility and legitimacy of the science and inhibits its use by decision-makers (Crona and Parker 2011).

This communication gap has ultimately pointed to the lack of a true counterpart to SAC, i.e., a regional scientific body composed of select scientific experts who can describe high-level climate science endeavors that may help address regional management priorities. A boundary organization should have representatives from the policy community, science community, as well as mediators to promote collaboration. While the NW CSC had strong representation from the policy community through its SAC and ready facilitators in its organizational leaders, it was lacking scientific representation on par with the SAC. To that end, the NW CSC has established a Science Advisory Panel (SAP) to engage in a dialogue with SAC members and advise the NW CSC on the most valuable actionable climate science for the region (Fig. 1B). SAP members are drawn from any number of scientific disciplines related to climate 
change and climate change impacts (e.g., atmospheric science, water resources, ecology, forestry, sociology, etc.), but they must be able to satisfy a number of additional eligibility criteria, such as the ability to: 1) describe and summarize the collective climate change efforts of individual PIs in broader, higher-level terms, 2) envision and have experience with large-scale interdisciplinary research initiatives with broad geographic reach, 3) outline the uncertainties and limitations associated with the use of scientific findings and products in resource management applications, 4) effectively convey complex climate change concepts to executives such as those represented in the SAC, and 5) demonstrate experience in co-producing actionable science with natural and cultural resource managers. An important qualification for any member should be a genuine commitment to advancing a regional climate science agenda aimed at meeting clearly-stated resource management priorities.

With the creation and maturation of a SAP, we can now envision a revised framework to develop and maximize delivery of co-produced actionable climate science at both the project and program levels (Fig. 1B). In this framework, each level will have a scientific and management component, and both levels will be linked to one another. The PI and resource manager working at the project level continue to collaborate as previously described. Regardless of whether the manager and corresponding agency executive successfully exchange information, the addition of a SAP addresses the first challenge identified earlier by creating a new alternate pathway that circumvents any potential inadequacies presented by each organization's information use environment and provides an optional conduit for the flow of scientific capacity between project and program level.

We believe that the establishment of the SAP will complete the required elements of a boundary organization in the NW CSC and facilitate regional-scale collaboration and co-production of knowledge in several ways. First, it will allow resource management executives assembled in the SAC to converse with an analogous body that convenes prominent scientific experts in the region. This ongoing dialogue between SAP members and their SAC counterparts, with the NW CSC core leadership acting as 
facilitators, sets up a new platform for communication and exchange that contemplates high-level programmatic considerations and far-reaching science endeavors.

In practice, the two groups meet regularly and aid one another in expressing and refining resource management priorities and appropriate scientific responses. Importantly, the presence of a SAP helps tackle the second challenge identified above by reframing conversations and encouraging SAC members to describe their organizations' management priorities in no uncertain terms, and SAP scientists to describe the potential for science to address those priorities. Although SAP representatives are not responsible for writing the Science Agenda (see explanation below), we suggest that the collaborative relationship and communication between the SAC and SAP will contribute to the production of a long-term Science Agenda that acts as a boundary object, in that it is an object that is common to and meaningful to both parties. The Science Agenda should elucidate management priorities while also clarifying the science needed to address those management priorities.

A significant body of research has demonstrated that interaction between scientists and decision-makers increases the use of science by decision-makers because it is perceived as more credible, legitimate, and salient (van de Vall and Bolas 1982; Oh and Rich 1996; Amara et al. 2004; Meagher et al. 2008; Dilling and Lemos 2011). We believe that creating this forum for the SAC and SAP to interact regularly will, as Crona and Parker (2011) suggest, increase the use of NW CSC science as decision-makers become more familiar with the science and researchers become more aware of decision-maker needs.

Second, we expect the presence of the SAP will provide a pathway for dialogue between the SAP and individual PIs. The SAP focuses on key programmatic management issues highlighted by the SAC and provides guidance in catalyzing and identifying key scientific directions at the core of the NW CSC 5-year Science Agenda. In this conversation, PIs should describe emerging scientific discoveries and discuss ways to package them efficiently for broad dissemination that secures maximum benefits to the end 
user community. Creating this opportunity for engagement between scientists working at different scales helps to broaden the science-policy network even more as individual PIs are drawn into discussions about regional-scale management decisions. We envision this process as somewhat analogous to the indirect network effects described by Crona and Parker (2011), in which policy makers not directly involved with the boundary organization are still exposed to its research through their ties with directly connected policy makers. In this case, scientists working at site-level projects may be linked more effectively to regional-scale management needs.

Because of this constant exposure to the latest scientific accomplishments in and out of the region, the SAP may now help resolve the third identified challenge: from their program or region-level vantage point, they are best positioned to bundle, format, and deliver the right kind and amount of scientific information necessary for SAC consumption. Facilitating this information packaging and communication flow is, according to Cash (2001), one of the primary roles of boundary organizations. Because the SAC is the focal point for the knowledge transfer, the individual SAC members may go on to become sources of information or nodes (Crona and Parker 2011) within their decision-maker networks, facilitating the flow of knowledge through their agencies. If successful, the scientific contribution may resonate louder and last longer during the formulation of climate adaptation plans and actions.

\section{Testing the framework: the SAC-SAP experiment}

For the NW CSC, the most immediate goal of enabling a regional resource management science dialogue is to develop the NW CSC Science Agenda for 2017-2022, a document which will guide the research activities and funding allocations of the NW CSC for the next five years. To that end, the NW CSC has begun building and testing the framework presented in Fig. 1B by recruiting SAP members, facilitating information sharing and conversations between SAC and SAP members, and convening remote and in-person meetings between the two groups. 
SAP members were selected based on the criteria described earlier, as well as geographic location (we sought representation from each state the NW CSC serves) and institutional affiliation (we sought representation from federal and state agencies, tribes, and Northwest academic institutions). SAP members were introduced to the full SAC through webinar meetings, and then SAP and SAC members were invited to participate in subgroups to facilitate further conversation. The subgroups were created by sorting and categorizing the large number of management goals the NW CSC has received from SAC members over the past two years through meetings, in-person interviews, questionnaires, and surveys.

NW CSC staff convened and facilitated webinar meetings for each of the subgroups; these conversations were crucial for allowing SAP members to ask clarifying questions about the desired resource management outcomes that SAC members had provided. SAP members then assessed the current state of knowledge for the management goals within each subgroup and identified and helped frame science opportunities for the NW CSC Science Agenda for 2017-2022. Again, the creation and eventual adoption of this Science Agenda, which has been intentionally and unambiguously designed to respond to resource management priorities, will be our primary measure of success for the SAC-SAP experiment.

There have been some challenges in creating and administering the SAP effort. First, there may be a perception of conflicts of interest for SAP members who may wish to apply for NW CSC funding in the future. To alleviate this, we emphasize that SAP members participate strictly on an advisory capacity (i.e., without decision-making authority) over the final contents of the NW CSC Science Agenda, and we do not allow them to draft language for the Science Agenda or subsequent solicitations for project proposals. Second, limited budgets prevent us from compensating SAP members for their time and work, therefore our use of their time must be very modest and efficient. Third, in order to maintain a manageable group size, we cannot include experts from every scientific sub-discipline that may be 
needed to fully address all high priority management priorities. To fill in these gaps, we ask SAP members to consult with appropriate experts on an as-needed basis. Finally, the logistics of managing full SAC-SAP in-person meetings can be complicated, from procuring facilitation services to finding dates that are open on everyone's calendars. However, the benefits of having the SAP engage with the SAC and NW CSC staff has so far greatly outweigh any of the challenges presented here.

\section{Conclusions}

In the six years since its establishment, the NW CSC has grown resolute and had early successes in its mission to co-produce actionable science for coping with climate change. The center's various processes for achieving this at the project level, between individual PIs and resources managers, continue to evolve and improve, but they are already yielding relationships and scientific products that are highly useful for climate change planning and decision-making. The processes used to exchange scientific information and resource management priorities at the program level now need to expand to fully harness the regional scientific expertise and allow the NW CSC to realize its potential as a boundary organization. We suggest that a missing component was regional-scale scientific representation equal to the regional-scale policy representation found in the SAC. The establishment of a SAP as described here will help to create an alternate pathway for the flow of scientific capacity between project and program levels, enable individual SAC members to become information nodes within their decision-maker networks, increase decision-makers' familiarity with the science and researchers' familiarity with resource management contexts, and facilitate regional-scale collaboration and co-production of knowledge. While the constitution of a SAP itself will not provide the ultimate panacea that resolves every issue hindering productive communications between scientists and resource managers, we are confident that this will result in a significant improvement in the co-production of actionable climate 
science. If successful, this model will facilitate greater sharing and use of scientific information to help us respond to our most pressing climate change issues.

Fig. 1 Information flow diagram depicting communication pathways between actors in the purview of the U.S. Department of the Interior Climate Science Centers (CSCs). A) The actors and information flows as CSCs currently experience them, with actionable science being successfully co-produced at the project level, but not necessarily at the program level. B) The idealized actors and information flows that would enable CSCs to successfully deliver actionable science at both the project and program levels. $\mathrm{PI}=$ project principal investigator, $\mathrm{MGR}=$ resource manager, $\mathrm{EX}=$ management agency executive, NW CSC = Northwest Climate Science Center, SAC = Stakeholder Advisory Committee, SAP = Science Advisory Panel. White block arrows = information flow for science capacity; black block arrows = information flow for management priorities; hatched arrow = incomplete information flow of management priorities; solid black line arrows = frequent communication between the NW CSC and other actors; dashed black line arrows = occasional communication between the NW CSC and other actors; question marks = incomplete knowledge of how information flow occurs.

\section{References}

ACCCNRS (Advisory Committee on Climate Change and Natural Resource Science) (2015) Report to the Secretary of the Interior.

https://nccwsc.usgs.gov/sites/default/files/files/ACCCNRS Report 2015.pdf. Accessed 4 January $\underline{2016}$

Amara N, Ouimet M, Landry R (2004) New evidence on instrumental, conceptual, and symbolic utilization of university research in government agencies. Sci Commun 26:75-106 
Beier P, Hansen LJ, Helbrecht L, Behar D (2017) A how-to guide for coproduction of actionable science. Cons Lett 10:288-296

Bell S, Shaw B, Boaz A (2011) Real-world approaches to assessing the impact of environmental research on policy. Res Evaluat 20:227-237

Cash, DW (2001) "In Order to Aid in Diffusing Useful and Practical Information": Agricultural Extension and Boundary Organizations. Sci Technol Hum Val 26:431-453

Cash DW, Borck JC, Patt AG (2006) Countering the loading-dock approach to linking science and decision making - Comparative analysis of El Nino/Southern Oscillation (ENSO) forecasting systems. Sci Technol Hum Val 31:465-494

Choo CW (2006) The knowing organization. Oxford University Press, New York

Crona BI, Parker JN (2011) Network determinants of knowledge utilization. Sci Commun 33:448-471

Cvitanovic C, Hobday AJ, van Kerkhoff L, Marshall NA (2015) Overcoming barriers to knowledge exchange for adaptive resource management; the perspectives of Australian marine scientists. Mar Policy 52:38-44

Dilling L, Lemos MC (2011) Creating usable science: Opportunities and constraints for climate knowledge use and their implications for science policy. Global Environ Chang 21:680-689

DOI (United States Department of the Interior) (2009) Secretarial Order No. 3289: Addressing the impacts of climate change on America's water, land, and other natural and cultural resources. http://elips.doi.gov/app_so/act_getfiles.cfm?order_number=3289A1. Accessed 4 January 2016

Guston, DH (1999) Stabilizing the boundary between U.S. politics and science: the role of the Office of Technology Transfer as a boundary organization. Soc Stud Sci 29:87-111

Guston, DH (2001) Boundary organizations in environmental policy and science: an introduction. Sci Technol Hum Val 26:399-408 
Lemos MC, Morehouse BJ (2005) The co-production of science and policy in integrated climate assessments. Global Environ Chang 15:57-68

Meadow AM, Ferguson DB, Guido Z, Horangic A, Owen G, Wall T (2015) Moving toward the deliberate coproduction of climate science knowledge. Weather Climate Soc 7:179-191

Meagher L, Lyall C, Nutley S (2008) Flows of knowledge, expertise and influence: a method for assessing policy and practice impacts from social science research. Res Evaluat 17:163-173

NCCWSC (National Climate Change and Wildlife Science Center). 2014. Climate Science Center Stakeholder Advisory Committee (SAC) terms of reference. NCCWSC, Reston, Virginia

Oh CH, Rich RF (1996) Explaining use of information in public policymaking. Knowledge and Policy 9:335.

Reed MS, Stringer LC, Fazey I, Evely AC, Kruijsen JHJ (2014) Five principles for the practice of knowledge exchange in environmental management. J Environ Manage 146:337-345

Roux DJ, Stirzaker RJ, Breen CM, Lefroy EC, Cresswell HP (2010) Framework for participative reflection on the accomplishment of transdisciplinary research programs. Environ Sci Policy 13:733-741

Taylor RS (1991) Information use environments. In: Dervin B, Voigt MJ (eds) Progress in communication science. Ablex Publishing Corporation, Norwood, NJ, pp 217-254

van de Vall M, Bolas C (1982) Using social policy research for reducing social problems: an empirical analysis of structure and functions. J Appl Behav Sci 18:49-67 


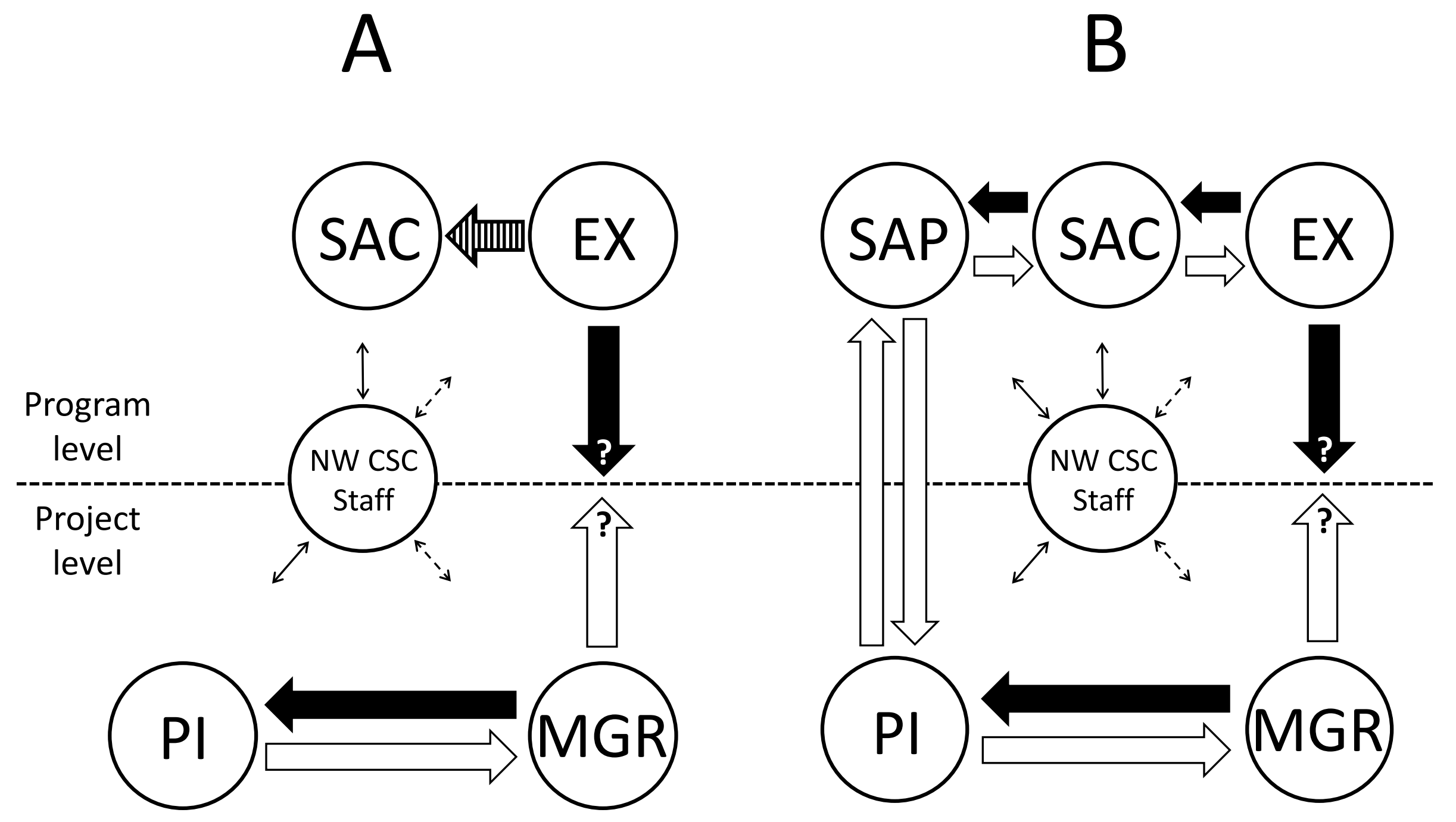

